\title{
HEMISPHERIC ASYMMETRY IN PROCESSING PLEASANT AND UNPLEASANT STIMULI - EMOTIONAL VALENCE PROCESSING
}

\author{
Sanja Budimir \\ Croatian Studies, Department of Psychology, \\ University of Zagreb \\ Borongajska cesta 83d, 10000 Zagreb \\ sbudimir@hrstud.hr \\ Ana Havelka Meštrović \\ RIT Croatia, Rochester Institute of Technology Croatia \\ Damira Tomljanovića Gavrana 15, 10000 Zagreb \\ ana.havelka-mestrovic@croatia.rit.edu \\ Marijan Palmović \\ Laboratory for Psycholinguistic Research, \\ University of Zagreb \\ Borongajska cesta 83f, 10000 Zagreb \\ palmovic@erf.hr
}

\begin{abstract}
Differences in electrophysiological response between pleasant and unpleasant emotional stimuli were examined in this study. Recording of event related potentials (ERP) was organized in such a way that the participants, 24 female students from the University of Zagreb, were first exposed to a priming stimulus (emotional pictures) followed by a target stimulus (emotional pictures). Adjusted pictures from the IAPS database (The International Affective Picture System) were used both for primes and target stimuli. Intensity and dominance of the pictures were controlled by using only pictures with medium values, while emotional valence was manipulated through three categories of pictures, unpleasant, neutral and pleasant. In order to detect differences in processing different emotional valence stimuli, measurement of the ERP signal was carried out with 180 emotional pictures (60 of each emotional valence) combined with three sets of priming stimuli, which made a total of 540 pairs of presented stimuli. The signal was recorded over frontal electrodes, and the results were analysed in the time window of 300-400 ms. The goal of the study was to test hemispheric asymmetry in processing emotional versus neutral stimuli by controlling gaze to emotional content of the picture, intensity and dominance of the emotional pictures as well by enhancing possible differences in processing emotional stimuli by introducing preceding priming emotional stimuli. The priming effect was not found to be a significant contributor to the processing of emotional target stimuli. A difference was found on the left hemi-
\end{abstract}


sphere between processing pleasant and unpleasant target stimuli, as well as a difference between processing unpleasant and neutral target stimuli. Regardless of priming, a difference was found on the left and the right hemisphere between processing pleasant and unpleasant target stimuli, whereas a difference between processing unpleasant and neutral stimuli was found on the left hemisphere as well as difference between processing pleasant and neutral target stimuli on the right hemisphere.

Key words: IAPS (International Affective Picture System), ERP (Event Related Potential), emotional valence, frontal asymmetry

\section{INTRODUCTION}

Research of subjective states such as emotions, encounters challenges which include defining emotions, choosing a theoretical framework and controlling interfering factors to the recording of emotional processing. The importance of emotions is emphasized by Frijda (2007) who determined the function of emotions as a preparation for coping with important events while creating a strong motivational power by producing a state of readiness for action, and defining priorities in behaviour and experiences. Emotional processing requires the activation of different complex processes. Cognitive, motivational and emotional processes that are active during emotional engagement lead to a general increase in arousal which is enough to focus the organism on the emotion which is being experienced, and to activate itself into cognitive interpretation of the environment with the purpose of finding a reason for increased arousal and to name the emotion accordingly (Scherer, 2000). Cognitive neuroscience can contribute to understanding emotional processing through measuring neurological responses to emotional stimuli.

Within neuroscientific research of emotional processing, there are attempts to describe emotional processing through detection of hemispheric localization of specific emotional processes. There are four theoretical models which describe the hemispheric lateralization of emotional processing; "Right-Hemisphere Model,", "Valence Model", "Approach-Withdrawal" and "Behavioural Inhibition System Behavioural Activation System (BIS/BAS)") (Demaree, Everhart, Youngstrom \& Harrison, 2005). The difference between these models can be summarized by determining the type of emotional processing each model is focused on. The "Right Hemisphere Model" refers on the processes of perception of emotional stimuli, whereas other models refer to processes of expression and experience related to emotional processing. The "Approach-Withdrawal" model describes emotional states that drive specific behaviour while the "Behavioural Inhibition System - Behavioural Activation System (BIS/BAS)" is more focused on emotional traits.

According to the "Right Hemisphere Model", emotional perception is the specialization of the right hemisphere regardless of emotional valence. The "Valence Model" focuses on the hemispheric specialization for emotional processing, where the left frontal cortex is specialized for processing the experience of pleasant emo- 
tions, while the right frontal cortex is responsible for processing the experience of unpleasant emotions (Demaree et al, 2005).

Considering that research of hemispheric asymmetries related to emotional processing is not consistent within one model, and there are obvious differences between models as well, there is a need to detect and explain the possible sources of those inconsistencies. The source of disagreement between the "Valence Model" and the "Right Hemisphere Model" might be the focus on different components of the emotional system (Wager, Luan Phan, Liberzon \& Taylor, 2003). Emotional processing consists of a set of subsystems which are involved in the processing of different aspects of emotion for which the patterns of brain asymmetry for perceiving and expressing emotions might not be the same (Wagner \& Koutstall, 2002). According to Davidson (1995) there is a distinction between perception, experience, and expression of emotion, for which different neural substrates are responsible.

Another factor that can contribute to different results in this field of research can be the usa of different methods for detecting differences in processing emotional versus neutral stimuli, or even finer differences within emotional stimuli, the differences in processing between pleasant and unpleasant stimuli. Rapid processing of an affective stimuli is a critical aspect of emotional responsivity (Olofsson, Nordin, Sequeira \& Polich, 2008), so determining a temporal order of an affective Event Related Potential (ERP) response, measured by the electroencephalogram (EEG), can contribute to the detection of differences in neurological response to pleasant and unpleasant stimuli. ERP response offers millisecond's precision in studying emotional processes related to given stimuli, while differences in amplitudes and latencies of the responses to emotional stimuli provide multidimensional insight into the inner architecture of these processes (Olofsson et al, 2008). Previous ERP studies that used emotional pictures as stimuli have differed in the identified ERP components elicited by emotional stimuli and tasks. Olofsson et al. (2008) classified ERP responses in three categories: short (100-200 ms), medium (200-300 ms) and long latency (over $300 \mathrm{~ms}$ ) within which are P300 and slow waves. Within ERP research, more factors are to be controlled in order to detect the difference between processing stimuli of different emotional valence values. Valence level can modulate emotional effect if emotional arousal is controlled for (Conroy \& Polich, 2007). More specifically, pleasant pictures are found to elicit larger components for short latencies (100-300 ms) as a result of rapid selective attention or target detection (P3b subcomponent) (Olofsson et al., 2008). On the other hand, processing within 200-300 ms latency range reflects natural selective attention, select affectional arousing stimuli for future processing (Dolcos \& Cabeza, 2002). P3a and P $3 \mathrm{~b}$ components are indices of attentional and initial memory storage events, and slow wave is related to task demand that involves working memory processes (Conroy \& Polich, 2007). Similarities and differences between P300 and slow wave for affective stimulus parameters are not defined. P3a amplitude becomes larger over frontal central sites for unpleasant and pleasant stimuli compared to neutral stimuli, 
while $\mathrm{P} 3 \mathrm{~b}$ seems to be sensitive to both valence and arousal variations (Delplanque, Silvert, Hot \& Sequeira, 2005). So far, ERP results did not report valence dependent effects on these components (De Cesarei \& Codispoti, 2006, Cuthbert, Schupp, Bradley, Birbaumer, \& Lang, 2000). In general, ERP valence effects are not consistent and are without a strong conclusion about the nature of the effects of emotional valence ERPs (Olofsson et al., 2008). The suggestion for contributing to emotional valence ERP results lies in additional investigations of task demands and picture compositions, as attention related modulators of affective influence and emotional regulation (Bradley \& Lang, 2007; Hajcak \& Nieuwenhuis, 2006; Moser, Hajcak, Bukay \& Simons, 2006). Early ERP components are susceptible to non-affective perceptual features, such as simplicity of background images, which highlights the need for balanced stimuli categories (Olofsson et al., 2008) in the direction of controlling possible interfering factors, with the aim of detecting very fine differences in emotional processing. Differences in observed ERP components were mostly found between emotional (pleasant and unpleasant) and neutral stimuli, while differences within different emotional valence stimuli were not found to be consistent (Oloffson et al., 2008). The exception is the difference detected over occipital sites, which can be the effect of perceptual, and not emotional characteristics of pictures, where unpleasant pictures engage more focal attentional processing then pleasant valence pictures (Oloffson et al., 2008). According to Davidson (1995) a brain region of interest related to affective asymmetry for emotional processing is the prefrontal cortex, where ERP differences are found within different emotional values of emotional stimuli, as early ERP components in favour of increased activity for processing unpleasant pictures. However, the early ERP component is affected by perceptual characteristics such as simplicity background images (where simple background composition elicits greater amplitude than in complex scenes) (Olofsson et al., 2008), colour (Cano, Class \& Polich, 2009), and spatial frequency stimuli (Carretie, Hinojosa, Lopez-Martin \& Tapia, 2007). So, with regard to this, it is questionable whether the emotional value of the processed stimuli is the actual cause of recorded early ERP components, or the detected difference is a result of processing perceptual characteristics.

Before interpreting ERP signals as emotional responses, there is another component that needs to be taken into consideration. The assumption in ERP research is that the recorded EEG activity is a consequence of the content of presented stimuli. Stimuli available in the most commonly used database of emotional pictures (International Affective Picture System (IAPS) (Lang, Bradely \& Cuthbert, 2008) are assumed to be inducing emotional states of different emotional valence values by visual presentation of emotional content in the pictures. However, it is not clear whether the same elements of emotional pictures attract the attention of all perceivers in the same way, and if they look at the same elements for the same amount of time, whether that can influence recorded brain activity. Eye tracking research on the IAPS emotional pictures (Budimir \& Palmović, 2011) showed that there is 
a significant difference in the time participants spend looking at the background compared to figure area. Participants avoided looking at the unpleasant emotional content placed in the figure area of the picture, and spent more time looking at the emotionally neutral elements in the background, whereas its content attracted their attention. That gaze pattern was not observed when neutral or pleasant pictures were presented. The time spent looking at certain stimuli has an effect on the recorded electrical activity which is expected to be related to the processing of presented stimuli. If this is not controlled for, the differences in electrical activity might be biased by the factor of time spent on the parts of the picture that are irrelevant for emotional processing that is intended to be captured. So, in order to ensure that recorded activity is a consequence of processing presented stimuli, important factors to be controlled for are elements of the content of presented stimuli. For that purpose, adjustments of IAPS pictures were made in this study by replacing background elements on each picture with a white background.

In addition, to enhance the effect of emotional processing, a priming picture preceded each stimulus picture. Within cognitive psychology and cognitive neuroscience, the term priming refers to the changes in which an earlier encounter with a specific stimulus (word, face, object) is replaced by a subsequent response to the same or related stimulus by increasing the speed and accuracy of answering, leading to deviations from the expected natural responses (Wagner \& Koutstaal, 2002). Affective priming occurs in emotional processing where there is a facilitated response to a particular stimulus if it is preceded by a prime of the same emotional value (Avero \& Calvo, 2006). It was expected that previous exposure to priming stimuli will interfere with processing of target emotional stimuli which would allow detecting a clearer distinction between processing unpleasant and pleasant processing. The priming pictures, emotionally congruent or incongruent to the stimulus pictures were introduced in this research to modify the electrophysiological response on the target pictures, i.e. to disassociate various stages of the emotional processes as reflected in the ERP response.

In order to determine the difference in neural electrophysiological activity between processing pleasant and unpleasant emotions, adjusted emotional pictures were presented in this research as priming and target emotional stimuli, while activity was analysed specifically for the left and the right hemisphere on frontal electrodes in 300-400 ms time window, which is also expected to reflect the cognitive component of emotional processing and not only the perception process. It is expected that the difference between pleasant and unpleasant processing will be detected as more positive activity during processing pleasant emotions on left electrodes compared to unpleasant emotions, and more positive activity on the right electrodes during processing unpleasant emotions compared to pleasant emotions. It is expected that the "Valence Model" will be confirmed, as a consequence of usage of adjusted emotional stimuli and priming stimuli which are expected to increase the detection of fine differences between processing stimuli of different emotional valence. 


\section{METHOD}

\section{Participants}

The participants were 24 undergraduate and graduate female students from the University of Zagreb, selected on the basis of gender and right hand dominance. Control of those two factors, gender and hand dominance is important because emotional stimuli used in this research are calibrated on the female population due to the gender differences in processing emotional stimuli, and hand dominance could possibly influence the recorded lateralization of emotional processing. The average age was 22 years $(\mathrm{M}=22.04, \mathrm{SD}=1.40)$. The average score on the Edinburgh Handedness Inventory (EHI) was $\mathrm{M}=82.71$ indicating distinct dominance of the right hand. Participants had no neurological or other disorders and were not under any pharmaceutical treatment, which is important because any aberration from normal population could potentially influence recorded EEG activity and consequently ERP signal.

\section{Procedure}

The research was conducted in the Laboratory for Psycholinguistic Research at the University of Zagreb. Each participant signed an informed consent with a detailed explanation of the experimental procedure, it was emphasized that their participation is voluntary, and that they can decline further participation at any moment. The study was approved by the Ethics Committee of the University of Zagreb. After signing an informed consent and completing the Edinburgh Handedness Inventory (Oldfield, 1971), EEG recording was conducted.

The task in the experiment was to observe the screen on which adjusted pleasant, unpleasant and neutral IAPS pictures were presented. Participants were exposed to three sets of 180 (60 pleasant, 60 neutral and 60 unpleasant) emotional pictures presented as target stimuli, preceded by the same randomly assigned priming pictures. Three sets differed by the emotional valence of priming stimuli (pleasant, neutral, and unpleasant) followed by three sets of different emotional valence of target stimuli. Each participant saw 540 target emotional pictures, which were preceded by the 540 priming emotional pictures $(3 \times 180)$.

After the fixating cross $(300 \mathrm{~ms})$, the priming stimulus was shown $(50 \mathrm{~ms})$ followed by a brief break $(100 \mathrm{~ms})$ before the target stimulus $(600 \mathrm{~ms})$. Within the experiment, subjects had two breaks, the first break occurred after 180 stimuli, and the second break after 360 stimuli were presented. Pause duration was controlled by the subjects pressing the ENTER key to continue displaying stimuli. The duration of presenting stimuli in the experiment was 9.5 minutes, and with breaks, the average duration of the experiment was around 11 minutes. 
Two separate two-factor repeated measures ANOVA $3 \times 3$ for each hemisphere were used.

Factors are: Priming (unpleasant, neutral and pleasant) $\times$ Target emotion (unpleasant, neutral and pleasant). Dependent variable was mean ERP amplitude measured over frontal electrodes in the time window $300-400 \mathrm{~ms}$.

\section{Instruments}

\section{Edinburgh Handedness Inventory}

Edinburgh Handedness Inventory (EHI: Oldfield, 1971) is a questionnaire that examines dominance of the left or right hand in daily activities. Participants need to evaluate which hand they use during ten daily activities. The total score is obtained by summarizing total the score for the left and right hand, and then the difference between the two results is divided by the total number of activities and multiplied by 100 . Results below -40 indicate dominance of the left hand, results between -40 and 40 indicate that the participant is using both hands equally and results above 40 indicate dominance of the right hand in performing everyday activities.

\section{International Affective Picture System (IAPS)}

The emotional stimuli used in this study are emotional pictures from the International Affective Picture System (IAPS, Lang et al., 2008). Pictures are chosen based on normative ratings for female adult participants, as there are different ratings depending on gender and age (adults/children). All pictures in the database are categorized on a 9 point scale according to their values for emotional valence, arousal and dominance. Criteria for choosing pictures were that arousal and dominance values have neutral values (range from 4 to 6). Unpleasant pictures were chosen in the range from 1 to 3 , neutral pictures in the range from 4 to 6 and pleasant pictures in the range from 7 to 9 . Mean normative ratings for pleasant pictures, based on female ratings, were: valence 7.51 (SD 1.54), arousal 5.00 (SD 2.44), dominance 5.76 (SD 2.09). Mean normative ratings for neutral pictures: valence 4.99 (SD 1.75), arousal 4.66 (SD 2.11), dominance 5.10 (SD 2.01). Mean normative ratings for unpleasant pictures were: valence 2.50 (SD 1.52), arousal 5.26 (SD 2.22), dominance 4.22 (SD 2.17). Additionally, pictures were adjusted for the purpose of this research in the way that background content on each picture was removed and replaced with a white background by using Adobe Photoshop CS2 software.

$E E G$

Stimuli were presented with the E-Prime software (Psychology Software Tools, Inc.) on the screen (size: $48 \times 30 \mathrm{~cm}$, Samsung SynMster T220) which was 1 meter 
away from the subjects. Brain Products Recorder (Brain Products GmbH, Munich, Germany) was used for recording the EEG signal on the QuickAmp128 amplifier (Brain Products $\mathrm{GmbH}$, Munich, Germany) and 32 channel actiCAP electrodes (Brain Products $\mathrm{GmbH}$, Munich, Germany) with $1 \mathrm{kHz}$ sampling rate. The electrodes were arranged according to the 10-10 system. Eye movements were recorded on two bipolar electrodes (HEOG, VEOG). Vision Analyzer software was used for signal analysis. Trigger signals were sent via E-Prime software (Psychology Software Tools, Inc., Pittsburgh, USA). During the experiment EEG, VEOG, and HEOG signals were recorded. EEG was recorded from 34 electrodes in which the sampling frequency was $1000 \mathrm{~Hz}$. The analysis of event related potentials was carried out off-line. Correction of ocular artefacts was applied to all 32 EEG channels based on Gratton and Coles's algorithm for each EEG channel. After artefact correction and low pass filtering $(30 \mathrm{~Hz})$, the recorded signal was segmented into $1100 \mathrm{~ms}$ long segments (from $-100 \mathrm{~ms}$ to $1000 \mathrm{~ms}$ after the stimulus onset). The segmented data were averaged and the mean values were calculated for the 300$400 \mathrm{~ms}$ time window, separately for each participant and for each condition, after which the mean value for all subjects in all conditions was calculated for each channel separately.

\section{Statistics}

Numerical data were analysed in SPSS 17 (Polar Engineering and Consulting). GLM (General Linear Model) for repeated measures was used to calculate the difference in activity of the frontal cortex in all nine conditions. Using the Bonferroni post hoc test, differences between different conditions were calculated for left and right hemisphere separately. Considering that data did not meet the criteria of sphericity, Greenhouse-Geisser correction of degrees of freedom was calculated and used for analysing the results.

\section{RESULTS}

In order to detect differences between processing emotional stimuli of different valence values, mean ERP amplitudes were analysed for nine sets of priming and target stimuli. Unpleasant, neutral and pleasant priming preceded unpleasant, neutral and pleasant target stimuli. Mean ERP amplitude was analysed in the 300-400 ms time window for the signal recorded over frontal electrodes. Considering different combinations of priming and target stimuli, one unique example of the recorded ERP signal was not expected. Results indicate that emotional pictures of different emotional valences produce different cortical responses, and the closest depiction of this difference is shown on Figure 1 where three different emotional valences preceded by a neutral prime elicited a difference in the average cortical response. 


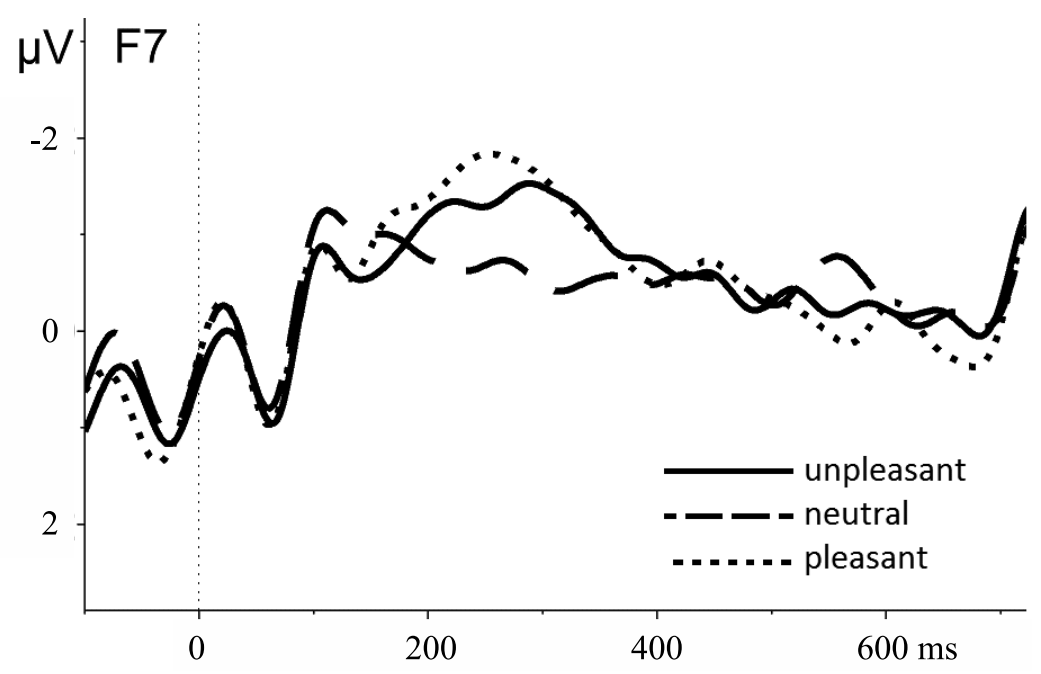

Figure 1. Averaged data for all three emotional valences with neutral prime

Generally, the priming paradigm produced a complex pattern of results which cannot be uniquely described by one sample of an ERP wave. On the other hand, priming was not found to give a statistically significant contribution in the direction of increasing or decreasing the emotional effect of the target stimuli (Table 1). For that reason, the waves with neutral priming were presented as an example of an ERP wave (Figure 1), and it can be seen that there is a visible change in the amplitude in the period from $200 \mathrm{~ms}$ to $400 \mathrm{~ms}$ as a result of processing target stimuli with different emotional valences. Not only do ERP waves for processing neutral and emotional (pleasant and unpleasant) target stimuli differ, but there is a difference between processing pleasant and unpleasant target stimuli. A similar ERP wave pattern is visible on both hemispheres, on the left and right frontal electrodes (F3, F4, F7, and F8) with smaller differences in the beginning and duration of differences in the amplitude between different priming and target stimuli.

Statistical analysis showed that the main effect of target emotion is statistically significant, while main effects of prime and interaction of prime and target have not been found to be statistically significant, on both left and right electrodes (Table 1a, Table 1b).

In other words, a significant difference in processing emotional target stimuli was found regardless of the effect of emotional valence of the priming stimuli. Considering that it is not justified to compare activity in different hemispheres by using EEG, as there is no spatial reliability of recorded electrical activity on the brain surface, only a comparison of different experimental conditions within one hemisphere can be made. A comparison within each hemisphere (Table 2) between different conditions was analysed. 
Table 1a. Tests of Within-Subjects Effects in the time window 300-400 ms, recorded over left frontal electrodes

\begin{tabular}{lcccrccc}
\hline Source & $\begin{array}{c}\text { Type III Sum } \\
\text { of Squares }\end{array}$ & df1 & df2 & Square & \multicolumn{1}{c}{ F } & Sig. & Partial $\eta^{2}$ \\
\hline Priming & 6.808 & 1.814 & 39.906 & 3.753 & 2.179 & 0.131 & 0.090 \\
Target & 39.365 & 1.907 & 41.955 & 20.642 & 10.282 & $0.000^{*}$ & 0.318 \\
Priming * Target & 6.924 & 2.392 & 52.619 & 2.895 & 1.102 & 0.348 & 0.048 \\
\hline
\end{tabular}

Degrees of freedom were corrected using Greenhouse-Geisser estimates of sphericity.

Table 1b. Tests of Within-Subjects Effects in the time window 300-400 ms, recorded over right frontal electrodes

\begin{tabular}{lccccccc}
\hline Source & $\begin{array}{c}\text { Type III Sum } \\
\text { of Squares }\end{array}$ & df1 & df2 & Square & F & Sig. & Partial $\eta^{2}$ \\
\hline Priming & 1.001 & 1.663 & 36.595 & 0.602 & 0.250 & 0.740 & 0.011 \\
Target & 27.182 & 1.881 & 41.371 & 14.455 & 8.832 & $0.001 *$ & 0.286 \\
Priming * Target & 9.437 & 2.274 & 50.037 & 4.149 & 1.644 & 0.200 & 0.070 \\
\hline
\end{tabular}

Degrees of freedom were corrected using Greenhouse-Geisser estimates of sphericity.

Table $2 a$. Difference between Target emotions in the mean ERP amplitude on left frontal electrodes (time window 300-400 ms)

\begin{tabular}{|c|c|c|c|c|c|c|}
\hline \multirow[b]{2}{*}{ Target emotion } & \multirow[b]{2}{*}{ Target emotion } & \multirow[b]{2}{*}{$\begin{array}{c}\text { Mean } \\
\text { Difference (I-J) }\end{array}$} & \multirow[b]{2}{*}{ Std. Error } & \multirow[b]{2}{*}{$\mathrm{p}$} & \multicolumn{2}{|c|}{$\begin{array}{c}95 \% \text { Confidence } \\
\text { Interval for Difference }\end{array}$} \\
\hline & & & & & $\begin{array}{l}\text { Lower } \\
\text { Bound }\end{array}$ & $\begin{array}{l}\text { Upper } \\
\text { Bound }\end{array}$ \\
\hline \multirow[t]{2}{*}{ Unpleasant } & Neutral & $-1.050 *$ & 0.213 & $0.000 *$ & -1.600 & -0.499 \\
\hline & Pleasant & $-0.696^{*}$ & 0.234 & $0.021 *$ & -1.303 & -0.089 \\
\hline \multirow[t]{2}{*}{ Neutral } & Unpleasant & $1.050 *$ & 0.213 & $0.000 *$ & 0.499 & 1.600 \\
\hline & Pleasant & 0.354 & 0.258 & 0.551 & -0.314 & 1.021 \\
\hline \multirow[t]{2}{*}{ Pleasant } & Unpleasant & $0.696^{*}$ & 0.234 & $0.021 *$ & 0.089 & 1.303 \\
\hline & Neutral & -0.354 & 0.258 & 0.551 & -1.021 & 0.314 \\
\hline
\end{tabular}

Based on estimated marginal means

* The mean difference is significant at the 0.05 level.

b Adjustment for multiple comparisons: Bonferroni 
Table $2 b$. Difference between Target emotions in the mean ERP amplitude on right frontal electrodes (time window 300-400 ms)

\begin{tabular}{|c|c|c|c|c|c|c|}
\hline \multirow[b]{2}{*}{ Target emotion } & \multirow[b]{2}{*}{ Target emotion } & \multirow[b]{2}{*}{$\begin{array}{c}\text { Mean } \\
\text { Difference (I-J) }\end{array}$} & \multirow[b]{2}{*}{ Std. Error } & \multirow[b]{2}{*}{$\mathrm{p}$} & \multicolumn{2}{|c|}{$\begin{array}{c}95 \% \text { Confidence } \\
\text { Interval for Difference }\end{array}$} \\
\hline & & & & & $\begin{array}{l}\text { Lower } \\
\text { Bound }\end{array}$ & $\begin{array}{l}\text { Upper } \\
\text { Bound }\end{array}$ \\
\hline \multirow[t]{2}{*}{ Unpleasant } & Neutral & 0.142 & 0.206 & 1.000 & -0.390 & 0.675 \\
\hline & Pleasant & $-0.688^{*}$ & 0.190 & $0.005^{*}$ & -1.181 & -0.194 \\
\hline \multirow[t]{2}{*}{ Neutral } & Unpleasant & -0.142 & 0.206 & 1.000 & -0.675 & 0.390 \\
\hline & Pleasant & $-0.830^{*}$ & 0.235 & $0.006^{*}$ & -1.439 & -0.220 \\
\hline \multirow[t]{2}{*}{ Pleasant } & Unpleasant & $0.688^{*}$ & 0.190 & $0.005^{*}$ & 0.194 & 1.181 \\
\hline & Neutral & $0.830 *$ & 0.235 & $0.006^{*}$ & 0.220 & 1.439 \\
\hline
\end{tabular}

Based on estimated marginal means

* The mean difference is significant at the .05 level

b Adjustment for multiple comparisons: Bonferroni

Processing of unpleasant stimuli differs from processing both pleasant and neutral stimuli on the left frontal electrodes and it is shown as a more positive activity for pleasant than for unpleasant emotions (Figure 2).

Also, processing of an unpleasant differs from processing a pleasant stimulus on the right hemisphere, where more positive activity is detected for pleasant com-

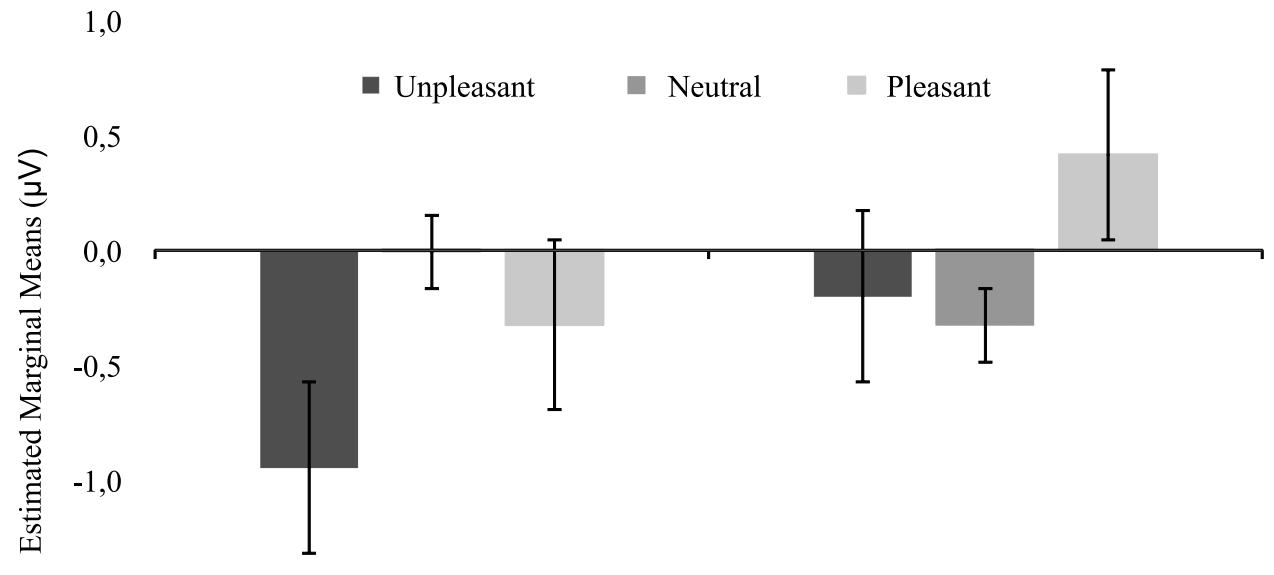

$-1,5$

Left

Hemisphere

Right

Figure 2. Estimated marginal means of ERP amplitude for unpleasant, neutral and pleasant target emotion on left and right frontal electrodes (time window $300-400 \mathrm{~ms}$ ) 
pared to unpleasant stimuli (Figure 2). Interestingly, a difference between processing pleasant and neutral target stimuli is also statistically significant, which is shown as more positive activity for processing pleasant stimuli compared to unpleasant and neutral, within the right hemisphere. These results indicate that a difference in processing stimuli of different emotional valence is emphasized regardless of the priming effect on both hemispheres. Generally, more positive activity is found from processing a pleasant stimulus compared to processing unpleasant stimuli, on both hemispheres.

\section{DISCUSSION}

The goal of this research was to detect differences in processing between pleasant and unpleasant target stimuli regarding hemispheric asymmetry which would contribute to confirmation of the Valence Model. It was expected that control of the factors such as the emotional content of the pictures, achieved through adjustments of the IAPS pictures, as well as control of the intensity and dominance of the emotional stimuli, and expected enhancing effect of priming stimuli, will contribute to the increase of a differences in processing stimuli of different emotional valence. Also, focus on only frontal electrodes in a narrow time window, 300-400 ms was made with the expectation of detecting the cognitive component of emotional processing, and to avoid the effect of perceptual processing that was shown in previous research (Davidson, 1995) by analysing earlier components.

Considering that prime effect was not found to be a significant factor that contributes to differences in processing emotional stimuli, it can be stated that emotional valence of a prime stimulus did not have an effect on the processing of emotional stimuli. Effect of affective priming is expected to disappear when participants become aware of the content of the priming stimuli as the critical element of the affective priming effect is unconscious processing (Lane \& Nadel, 2002). In this research, subliminal priming $(50 \mathrm{~ms})$ was used, and it was expected to induce the affective priming effect. Usage of the same sets of emotional stimuli for priming and target could have a possible contribution in recognizing and remembering pictures presented as target stimuli, and consequently annul the unconscious processing of the prime stimuli due to familiarity and recognition of the prime stimuli.

The main effect of target stimuli is found to be significant, but in order to interpret differences between processing different emotional stimuli, hemispheric localization needs to be taken into account. Considering the nature of EEG methodology which, on its own, provides only information about a temporal component of cognitive processing, comparison of activity from two different hemispheres is not justified, as a comparison of two different locations on the brain scalp is not representative of the actual localization of neural activity. So, interpreting differences in processing stimuli with different emotional valences, includes analysing 
results within one hemisphere by comparing activity due to different experimental conditions.

Processing of unpleasant stimuli differs from processing both pleasant and neutral stimuli on the left frontal electrodes. These results suggest that activity recorded on the left hemisphere differs depending on the emotional valence of the target stimuli, more specifically, the difference between pleasant and unpleasant processing was shown. Activity due to processing pleasant stimuli is more positive compared to processing unpleasant stimuli, which can be interpreted by the Valence Model, according to which, left hemisphere is more active due to processing of pleasant stimuli. On the other hand, a difference in processing between unpleasant and neutral targets was also found on the left hemisphere in the direction of more positive activity due to processing of neutral target stimuli, which emphasizes difference in activity due to processing of unpleasant stimuli compared to neutral or pleasant target stimuli localized on the left hemisphere. With this result, expectations were partially confirmed, as this result gives a contribution to the Valence Model by making a distinction between processing of pleasant and unpleasant stimuli on the left hemisphere. According to the same model, differences in processing between different emotional valences are expected to be found on the right hemisphere as well. Difference is expected in favour of the unpleasant stimuli in the way that right hemisphere is more responsive for processing of unpleasant stimuli. Results of this research do show a difference in processing different valence stimuli on the right hemisphere, difference between unpleasant and pleasant, as well as a difference between pleasant and neutral target stimuli. There is a trend of the same direction of differences on both hemispheres (Figure 2), as more positive activity for processing a pleasant stimulus compared to processing an unpleasant one. According to the results of this research, distinction between processing of stimuli of different valence can be made based on the activity on both, left and right hemisphere.

Main difference between two models of hemispheric asymmetry is in the type of emotional processing. Right Hemisphere Model refers to the emotional perception and perceptual identification of facial expression, which are dominantly a function of the right hemisphere, whereas Valence model refers to the expression of positive emotions at the stage of response preparation which is placed in the left hemisphere. Interestingly, results of this research show differences between processing pleasant and unpleasant stimuli on both right and left hemispheres. A possible explanation for differences found on the right hemisphere might be the type of stimuli used. Content of the stimuli used in this research differed within a category of the same emotional valence and included different contents, such as landscapes, portraits, animals and faces. Considering that both positive and negative sets of emotional stimuli included facial expressions, and participants did not have to react, but just to perceive the presented stimuli, results of this research emphasize that there are differences in the perception process of emotional stimuli between different valence emotional stimuli on the right hemisphere. Processing of pleasant stimuli shows 
higher and more positive activity compared to smaller and less positive activity for unpleasant stimuli. These results do not confirm the Valence model, according to which it is expected that the right hemisphere is more active due to the processing of unpleasant stimuli.

Differences in processing stimuli of different emotional valences were found on the left hemisphere as well. Processing of pleasant stimuli shows smaller but more positive activity compared to higher and less positive activity for unpleasant stimuli. Possible explanation for these differences can be found in the type of processing for which the left hemisphere is responsible, according to the Valence model, which assumes processing of cognitive component of emotional processing, and not only processing of perceptual characteristics. Considering the different content in the used stimuli, it can be assumed that differences on both hemispheres in processing pleasant and unpleasant stimuli are a reflection of different types of processing that is underlined in processing different emotional content within the same emotional valence category in the presented stimuli.

Attempts at determining hemispheric differences in processing pleasant and unpleasant stimuli still have not deliver clear confirmation of existed theories of emotional processing. As suggested by Davidson (1995), the reason might be that models are referring to different level and different type of emotional processing which exposes a need for distinguishing processes of emotional perception, expression and experience.

In order to detect clearer hemispheric differences between processing pleasant and unpleasant stimuli, whether the activity is recorded on the left or right hemisphere, it would be necessary to obtain a better control over the factors that are interfering in its detection. When trying to detect fine differences between processing pleasant and unpleasant stimuli, in the range of milliseconds, it is crucial to exclude other potential interfering variables. Future research that might be using affective priming could take into consideration the use of different stimuli for priming and target, as it is possible that use of the same stimuli in both categories could interfere with unconscious processing which is a crucial aspect for affective priming to have an impact. Due to the shortage of available stimuli for specific categories in IAPS database, it would be necessary to create a new database of emotional picture stimuli that would allow manipulation of factors such as intensity, dominance and valence, with specific content and sufficient number of stimuli per each category. Another suggestion for detecting an effect of emotional valence was to control arousal (Conroy \& Polich, 2007) and picture compositions (Bradley \& Lang, 2007; Hajcak \& Nieuwenhuis, 2006; Moser et al., 2006). Some factors were taken into consideration in this research by controlling not only arousal but also dominance of the presented stimuli, as well as composition by removing interfering elements in the background of the picture. Nevertheless, considering the nature of the used stimuli, where within the same category of emotional valence were pictures with different content (for example, pleasant pictures were landscapes, animals, and faces), using a controlled 
emotion stimuli emerges as an additional factor that needs to be controlled. Other than controlling the content of the pictures, there are other factors that can contribute to recorded brain activity, such as, brightness, size, constancy, visual acuity, contrast, colour discrimination on the presented stimuli (Capó-Aponte et al., 2009). These elements are not controlled in IAPS pictures, while they are the factors that can determine visual perception, and cognitive processing as well. For example, category of pictures used in this research categorized as pleasant, medium arousal and medium dominance has pictures of landscapes, animals, objects and people in the same category. So, it is not clear if the detected difference in processing emotional stimuli is actually due to differences in emotional value and not the content of pictures.

In this research, a difference between activity due to processing pleasant and unpleasant stimuli is detected in the later time window, so a suggestion for future research is to increase the length of the time window with the aim of detecting possibly longer cognitive processing related to emotional stimuli.

In general, before creating a research design to detect potential hemispheric differences in emotional processing, it is necessary to make a distinction between processes of emotional perception, expression and experience of emotion, by controlling the characteristics of the used stimuli, if possible. New stimuli, which would allow a better control of emotional content, technical characteristics of the stimuli, as well as the control of emotional valence, intensity and dominance, needs to be created in order to detect hemispheric difference between different emotional processes, perception, expression and experience.

\section{REFERENCES}

Avero, P. \& Calvo, M. G. (2006). Affective Priming with Pictures of Emotional Scenes: The Role of Perceptual Similarity and Category Relatedness. The Spanish Journal of Psychology , 9(1), 10-18.

Bradley, M. M. \& Lang P. J. (2007). Emotion and motivation. In: J.T. Cacioppo, I.G. Tassinary, \& G. Berntson (Eds.), Handbook of psychophysiology, 3rd ed (pp. 581-607). New York: Cambridge University Press.

Budimir, S., \& Palmović, M. (2011). Gaze differences in processing pictures with emotional content. Collegium Antropologicum, 35(1), 17-23.

Cano, M. E., Class, Q. A. \& Polich, J. (2009) Affective valence, stimulus attributes, and P300: color vs. black/white and normal vs. scrambled images. International Journal of Psychophysiology, 71, 17-24.

Capó-Aponte, J. E., Temme, L. A., Task, H. L., Pinkus, A. R., Kalich, M. E., Pantle, A. J. $\&$ Rash, C. E. (2009). Visual perception and cognitive performance. Helmet-Mounted Displays: Sensation, Perception and Cognitive Issues, 335-390.

Carretie, L., Hinojosa, J.A., Lopez-Martin, S. \& Tapia, M. (2007). An electrophysiological study on the interaction between emotional content and spatial frequency of visual stimuli. Neuropsychologia 45, 1187-1195. 
Conroy, M. A. \& Polich, J. (2007). Affective valence and P300 when stimulus arousal level is controlled. Cognition and Emotion, 21(4), 891-901.

Cuthbert, B. N., Schupp, H. T., Bradley, M. M., Birbaumer, N. \& Lang, P. J. (2000). Brain potentials in affective picture processing: covariation with autonomic arousal and affective report. Biological Psychology, 52(2), 95-111.

Davidson, R. J. (1995). Cerebral asymmetry, emotion, and affective style. In: R. J. Davidson, R. J. \& K. E. Hugdahl, K. E. (Eds.1995). Brain asymmetry (pp. 361-387). Cambridge, MA: The MIT Press.

De Cesarei, A. \& Codispoti, M., (2006). When does size not matter? Effects of stimulus size on affective modulation. Psychophysiology, 43, 207-215.

Delplanque, S., Silvert, L., Hot, P. \& Sequeira, H. (2005). Event-related P3a and P3b in response to unpredictable emotional stimuli. Biological Psychology, 68(2), 107-120.

Demaree, H. A., Everhart, D. E., Youngstrom, E. A. \& Harrison, D. W. (2005). Brain lateralization of emotional processing: historical roots and a future incorporating "dominance". Behavioral and Cognitive Neuroscience Reviews, 4(1), 3-20.

Dolcos, F. \& Cabeza, R. (2002). Event-related potentials of emotional memory: encoding pleasant, unpleasant, and neutral pictures. Cognitive, Affective, \& Behavioral Neuroscience, 2(3), 252-263.

Frijda N. H. (2007). The laws of emotion. Mahwah, NJ: Lawrence Erlbaum Associates.

Hajcak, G. \& Nieuwenhuis, S. (2006). Reappraisal modulates the electrocortical response to unpleasant pictures. Cognitive, Affective, \& Behavioral Neuroscience, 6(4), 291-297.

Lane, R. D. \& Nadel, L. (2002). Cognitive neuroscience of emotion. New York, NY: Oxford University Press.

Lang, P. J., Bradley, M. M. \& Cuthbert, B. N. (2008). International affective picture system (IAPS): Affective ratings of pictures and instruction manual. Technical report $A$ - 8 .

Moser, J. S., Hajcak, G., Bukay, E. \& Simons, R. F. (2006). Intentional modulation of emotional responding to unpleasant pictures: an ERP study. Psychophysiology, 43(3), 292-296.

Oldfield, R. C. (1971). The assessment and analysis of handedness: the Edinburgh inventory. Neuropsychologia, 9(1), 97-113.

Olofsson, J. K., Nordin, S., Sequeira, H. \& Polich, J. (2008). Affective picture processing: an integrative review of ERP findings. Biological Psychology, 77(3), 247-265.

Scherer, K. R. (2000). Psychological models of emotion. The Neuropsychology of Emotion, 137(3), 137-162.

Wager, T.D., Luan Phan, K., Liberzon, I. \& Taylor, S.F. (2003). Valence, gender, and lateralization of functional brain anatomy in emotion: a meta-analysis of findings from neuroimaging. Neuroimage, 19, 513-531.

Wagner, A.D. \& Koutstaal, W. (2002). Priming. In: Encyclopedia of the Human Brain Copyright, 4, 27, Elsevier Science (USA). 


\title{
HEMISFERNA ASIMETRIJA U PROCESIRANJU UGODNIH I NEUGODNIH PODRAŽAJA - PROCESIRANJE EMOCIONALNIH VRIJEDNOSTI
}

\begin{abstract}
Sažetak
U ovom istraživanju ispitane su razlike u elektrofiziološkom odgovoru između ugodnih i neugodnih emocionalnih podražaja. Snimanje kognitivnih evociranih potencijala je organizirano na način da su 24 ženske sudionice sa Sveučilišta u Zagrebu bile prvo izložene priming podražaju (emocionalne fotografije), a nakon toga ciljnom podražaju (emocionalne fotografije). Prilagođene fotografije iz IAPS baze (The International Affective Picture System) korištene su za obje vrste podražaja. Intenzitet i dominantnost emocionalnih fotografija je kontrolirana na način da su odabrane samo fotografije sa srednjim vrijednostima, a emocionalna vrijednost je manipulirana kroz tri kategorije fotografija: neugodne, neutralne i ugodne. S ciljem mjerenja razlika u procesiranju podražaja različitih emocionalnih vrijednosti, u mjerenju kognitivnih evociranih potencijala korišteno je 180 emocionalnih fotografija (60 fotografija iz svake kategorije emocionalnih vrijednosti), koje su kombinirane sa tri seta priming podražaja, što ukupno čini 540 parova prezentiranih podražaja. Signal je sniman iznad frontalnih elektroda, a rezultati su analizirani u vremenskom periodu od 300-400 ms. Cilj istraživanja je bio ispitati hemisfernu asimetriju u procesiranju emocionalnih nasuprot neutralnim podražajima, uz kontrolu pogleda na emocionalni sadržaj fotografije, intenzitet i dominantnost emocionalnih fotografija, uz potencijalno povećanje razlika uvođenjem priming emocionalnog podražaja. Priming efekt nije značajno doprinio razlikama u procesiranju emocionalnih ciljnih podražaja. Neovisno o primingu, razlika između procesiranja ugodnih i neugodnih ciljnih podražaja je pronađena i na lijevoj i na desnoj hemisferi, dok se razlika u procesiranju neugodnih i neutralnih pokazala na lijevoj hemisferi a razlika između ugodnih i neutralnih na desnoj hemisferi.
\end{abstract}

Ključne riječi: IAPS (International Affective Picture System), ERP (Event Related Potential-Kognitivni evocirani potencijali), emocionalna vrijednost, frontalna asimetrija 
